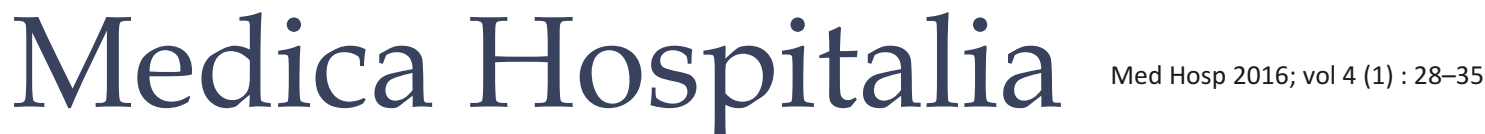

Original Article

\section{Perbandingan Tinggi Badan dan Rentang Tangan Pada Anak Usia Sekolah Dasar}

\author{
Jessica Wongsodjaja ${ }^{1}$, Maria Mexitalia ${ }^{2}$ \\ ${ }^{1}$ Mahasiswa program pendidikan S-1 Pendidikan Dokter FK UNDIP \\ ${ }^{2}$ Departemen IImu Kesehatan Anak Fakultas Kedokteran Universitas Diponegoro / RSUP Dr. Kariadi Semarang
}

\begin{abstract}
Abstrak
Latar belakang : Rentang tangan (RT) adalah parameter tubuh terbaik yang dapat dijadikan sebagai prediktor tinggi badan (TB), khususnya bagi anak dengan disabilitas atau deformitas ekstremitas bawah dan anak-anak yang dirawat di rumah sakit. Usia, jenis kelamin, dan suku bangsa adalah faktor yang berpengaruh terhadap tinggi badan, sehingga diperlukan suatu rumus perhitungan tinggi badan berdasarkan rentang tangan khusus untuk penduduk Indonesia. Penelitian ini bertujuan untuk mengetahui perbandingan tinggi badan dan rentang tangan anak usia sekolah dasar.

Metode : Rancangan penelitian adalah cross-sectional dengan observasional analitik. Penelitian ini dilakukan pada bulan April-Mei 2015. Besar subyek minimal adalah 29 subyek dan total responden penelitian adalah 335 responden. Pengukuran tinggi badan dan rentang tangan dilakukan dengan menggunakan stadiometer dan penggaris panjang yang terkalibrasi. Uji statistik menggunakan uji korelasi Pearson dan Spearman, kemudian dilakukan analisis regresi linier untuk mengetahui rumus perhitungan tinggi badan.

Hasil : Persamaan umum estimasi tinggi badan laki-laki adalah $\mathrm{TB}=15,615+0,879 \mathrm{RT}\left(\mathrm{r}=0,956, \mathrm{R}^{2}=91,7 \%\right)$ dan perempuan adalah $\mathrm{TB}=17,108+0,869 \mathrm{RT}\left(r=0,972, \mathrm{R}^{2}=94,9 \%\right)$. Rumus khusus estimasi tinggi badan untuk anak laki-laki usia 7 tahun adalah TB $=30,547+0,750 \mathrm{RT}$, sedangkan anak perempuan adalah $T B=29,476+0,764$ RT. Rumus khusus untuk anak laki-laki usia 8 tahun adalah TB $=24,119+0,801 \mathrm{RT}$, sedangkan anak perempuan adalah TB $=28,660+0,771 \mathrm{RT}$. Rumus khusus untuk anak laki-laki usia 9 tahun adalah TB $=26,190+0,801 \mathrm{RT}$, sedangkan anak perempuan adalah $T B=16,356+0,869 R T$. Rumus khusus untuk anak laki-laki usia 10 tahun adalah TB $=12,218+$ $0,906 \mathrm{RT}$, sedangkan anak perempuan adalah $\mathrm{TB}=11,347+0,918$ RT. Rumus khusus untuk anak laki-laki usia 11 tahun adalah TB = $26,117+0,801 R T$, sedangkan anak perempuan adalah $T B=22,269$ $+0,833$ RT. Rumus khusus untuk anak laki-laki 12 tahun adalah $\mathrm{TB}=31,881+0,773 \mathrm{RT}$, sedangkan anak perempuan $\mathrm{TB}=50,476+$ 0,648 RT.

Simpulan : Rentang tangan berkorelasi sangat kuat dengan tinggi badan, sehingga estimasi tinggi badan anak dapat dihitung dengan menggunakan rumus khusus per usia dan jenis kelamin yang lebih
\end{abstract}

\section{Comparison of height and arm span in school-aged children}

\begin{abstract}
Background: Arm span (AS) is the most accurate and reliable body parameter to predict the height $(\mathrm{Ht})$ of an individual, especially for children with disability or deformity in lower extremities and children who were hospitalized. Age, sex, and ethnic differences were associated to height. This confirmed the necessity to acquire specific height equation based on arm span for Indonesian people. Aim: The objective of this research was to determine the correlation between height and arm span of school-aged children. Methods : This was a cross-sectional study with observational analysis. This research was held from April until May 2015.Minimal sample for this study was 29 subjects and total number of subject was 335 subjects. Height and arm span were measured directly from subjects with stadiometer and calibrated ruler. The data were statistically analyzed with Pearson and Spearman test, and then a linear regression analysis was performed to acquire height equation.
\end{abstract}

Results : Equations for boys aged 6-12 years old were $\mathrm{Ht}=15.615+$ 0.879 AS $\left(r=0.956, R^{2}=91.7 \%\right)$ and $\mathrm{Ht}=17.108+0.869$ AS $\left(r=0.972, R^{2}=94.9 \%\right)$ for girls. Specific equations for 7 years old boys were $\mathrm{Ht}=30.547+0.750 \mathrm{AS}$ and $\mathrm{Ht}=29.476+0.764 \mathrm{AS}$ for girls. Specific equations for 8 years old boys were $\mathrm{Ht}=24.119+$ $0.801 \mathrm{AS}$ and $\mathrm{Ht}=28.660+0.771 \mathrm{AS}$ for girls. Specific equations for 9 years old boys were $\mathrm{Ht}=26.190+0.801 \mathrm{AS}$ and $\mathrm{Ht}=16.356+$ $0.869 \mathrm{AS}$ for girls. Specific equations for 10 years old boys were $\mathrm{Ht}=$ $12.218+0.906 \mathrm{AS}$ and $\mathrm{Ht}=11.347+0.918$ AS for girls. Specific equations for 11 years old boys were $\mathrm{Ht}=26.117+0.801 \mathrm{AS}$ and $\mathrm{Ht}$ $=22.269+0.833$ AS for girls. Specific equations for 12 years old boys were $\mathrm{Ht}=31.881+0.773 \mathrm{AS}$ and $\mathrm{Ht}=50.476+0.648 \mathrm{AS}$ for girls.

Conclusion : Arm span has a significant correlation with height. Specific equations for each group of age and sex were clinically significant to estimate height based on arm span as predictor.

Keywords : Anthropometry, height, arm span, school-aged children 
bermakna secara klinis.

Kata Kunci : Antropometri, tinggi badan, rentang tangan, anak usia sekolah dasar

\section{PENDAHULUAN}

Status gizi anak masih menjadi salah satu masalah yang dihadapi oleh berbagai negara di dunia. Kematian anak dunia akibat status gizi yang rendah mencapai setengah dari total kematian anak di bawah usia 5 tahun. Prevalensi kematian tersebut tinggi di negara-negara berkembang seperti di benua Asia dan Afrika. Satu dari empat anak di bawah usia 5 tahun di dunia mengalami pertumbuhan yang terhambat. Survei UNICEF pada tahun 2013 menunjukkan total anak dengan pertumbuhan yang terhambat mencapai 161 juta anak dan tersebar di wilayah Asia dan Afrika. ${ }^{1}$ Terhambatnya pertumbuhan anak saat dini dapat berpengaruh secara ireversibel saat anak beranjak dewasa.

Proses pertumbuhan dan perkembangan anak berlangsung sejak anak masih dalam kandungan dan berlanjut setelah anak lahir. ${ }^{2}$ Tahap pertumbuhan anak terbagi berdasarkan usia dan manifestasi tiap fase berbeda. Terdapat berbagai faktor yang mempengaruhi pertumbuhan dan perkembangan anak, antara lain asupan nutrisi sejak kecil, pola asuh orang tua, kehidupan sosial ekonomi, dan juga interaksi dengan lingkungan di luar rumah. ${ }^{3}$

Hambatan pertumbuhan anak dapat diketahui dengan pengukuran antropometri. Tinggi badan merupakan indikator yang paling sering digunakan untuk mengetahui adanya hambatan pertumbuhan. ${ }^{2}$ Tinggi badan seseorang dipengaruhi oleh berbagai faktor seperti genetik, jenis kelamin, suku bangsa, dan keadaan sosial ekonomi. ${ }^{4-6}$

Parameter tubuh lain dapat digunakan sebagai prediktor tinggi badan apabila anak memiliki disabilitas atau deformitas pada ekstremitas, penyakit genetik yang mempengaruhi proporsi tubuh, dan keadaan patologis tulang lainnya. ${ }^{4-6}$ Hasil penelitian menunjukkan bahwa rentang tangan memiliki korelasi yang signifikan terhadap tinggi badan sehingga rentang tangan dapat digunakan sebagai parameter untuk mengetahui tinggi badan seseorang. , $5,7-11$

Penelitian mengenai hubungan rentang tangan dan tinggi badan yang telah dilakukan sebelumnya umumnya mengambil subyek orang dewasa dan lansia, sedangkan subyek anak usia sekolah dasar masih terbatas. Faktor suku bangsa menyebabkan rumus perhitungan tinggi badan tiap negara akan berbeda, sehingga peneliti tertarik untuk mengetahui perbandingan tinggi badan dan rentang tangan pada anak usia sekolah dasar di Semarang mewakili Indonesia. Penelitian ini mengambil subyek anak usia sekolah dasar di SDN Karangrejo 01, SDN Bendungan, dan SDN Lempongsari, Kecamatan Gajah Mungkur, Semarang. Rumus perhitungan yang dihasilkan diharapkan dapat digunakan untuk mengetahui tinggi badan anak berdasarkan rentang tangan bagi anak yang sulit diukur tinggi badannya.

\section{METODE}

Penelitian ini merupakan penelitian observasional analitik dengan rancangan cross sectional. Penelitian dilakukan di SDN Karangrejo 01, SDN Bendungan, dan SDN Lempongsari, Kecamatan Gajah Mungkur, Semarang. Sampel penelitian diperoleh secara stratified random sampling yaitu 16 kecamatan di Semarang diacak untuk diambil 1 kecamatan, kemudian sekolah dasar dalam 1 kecamatan akan diacak untuk diambil 3 sekolah dasar. Subyek yang diambil dari 3 sekolah dasar tersebut akan dipilih berdasarkan kriteria inklusi yaitu anak usia 6-12 tahun dan setuju untuk ikut penelitian, sedangkan anak dengan disabilitas atau deformitas ekstremitas dan tulang belakang serta memiliki penyakit genetik seperti Marfan's syndrome tidak diikutsertakan. Total subyek penelitian ini adalah 335 responden. Analisis statistik dilakukan dengan menggunakan program SPSS 21.0 for Windows.

\section{HASIL DAN PEMBAHASAN}

Subyek penelitian terdiri atas 173 anak laki-laki (51,6\%) dan 162 anak perempuan (48,4\%). Jumlah subyek terbanyak adalah anak usia 11 tahun yaitu 76 anak dan paling sedikit adalah anak usia 6 tahun yaitu 3 anak. Rentang usia minimal adalah 6 tahun dan maksimal

\section{TABEL 1}

Hasil pengukuran antropometri total anak

\begin{tabular}{lccccc} 
Variabel & $\boldsymbol{n}$ & Minimal & Maksimal & Median & Rerata \pm SB \\
\hline Tinggi Badan & 335 & 108,7 & 158,8 & 132,1 & $131,2 \pm 10,37$ \\
Rentang Tangan & 335 & 105,7 & 160,2 & 132,2 & $131,4 \pm 11,49$ \\
\hline
\end{tabular}


TABEL 2

Hasil pengukuran antropometri anak berdasarkan jenis kelamin

\section{Variabel}

Tinggi Badan

Laki-laki
Perempuan

Rentang Tangan

$$
\text { Laki-laki }
$$

Perempuan n

Minimal

111,2

108,7

108,3

105,7
Maksimal

158,8

156,4

159,5

160,2
Median

132,6

129,2

132,5

130,1
Rerata \pm SB

$131,9 \pm 9,66$

$130,6 \pm 11,07$

$132,2 \pm 10,52$

$130,5 \pm 12,41$

\section{TABEL 3}

Korelasi tinggi badan (TB) dan rentang tangan (RT) total anak

Jenis Kelamin

Laki-Laki

Perempuan

* Uji Korelasi Spearman

\section{Koefisien Korelasi (r)*}

0,956

0,972 $\boldsymbol{p}$

$<0,001$

$<0,001$

TABEL 4

Hasil analisis regresi linier RT sebagai prediktor TB berdasarkan jenis kelamin

\begin{tabular}{lcccccc} 
Jenis Kelamin & Koefisien Korelasi & Standard Error & $\mathbf{R}^{\mathbf{2}}(\mathbf{\%})$ & $\boldsymbol{p}$ & a & b \\
\hline Laki-Laki & 0,956 & 2,784 & 91,7 & $<0,001$ & 15,615 & 0,879 \\
Perempuan & 0,972 & 2,494 & 94,9 & $<0,001$ & 17,108 & 0,869
\end{tabular}

\section{TABEL 5}

Hasil pengukuran TB anak laki-laki berdasarkan usia

\begin{tabular}{lcccc} 
Usia & $\mathbf{n}$ & Rerata \pm SB Tinggi Badan & Min-Maks & Median \\
\hline 6 Tahun & 1 & - & $112,5-133,0$ & - \\
7 Tahun & 24 & $118,9 \pm 4,83$ & $111,2-132,1$ & 118,2 \\
8 Tahun & 21 & $122,9 \pm 4,98$ & $119,6-144,2$ & 131,9 \\
9 Tahun & 30 & $131,2 \pm 5,49$ & $120,1-149,3$ & 132,9 \\
10 Tahun & 34 & $133,5 \pm 6,40$ & $128,7-157,6 *$ & $136,3^{*}$ \\
11 Tahun & 37 & $137,9 \pm 6,51^{*}$ & $123,3-158,8$ & 141,1 \\
12 Tahun & 26 & $141,7 \pm 7,46$ &
\end{tabular}

* Uji Non-parametrik 


\section{TABEL 6}

Hasil pengukuran RT anak laki-laki berdasarkan usia

\begin{tabular}{lcccc} 
Usia & $\mathbf{n}$ & Rerata $\mathbf{E}$ SB Rentang Tangan & Min-Maks & Median \\
\hline 6 Tahun & 1 & - & $108,3-130,0$ & - \\
7 Tahun & 24 & $117,9 \pm 5,31$ & $110,1-133,1$ & 116,7 \\
8 Tahun & 21 & $123,5 \pm 5,44$ & $117,0-140,8$ & 131,8 \\
9 Tahun & 30 & $131,1 \pm 5,86$ & $119,1-146,4$ & 133,6 \\
10 Tahun & 34 & $133,8 \pm 6,57$ & $129,1-158,5 *$ & $137,1 *$ \\
11 Tahun & 37 & $139,5 \pm 7,31^{*}$ & $118,4-159,5$ & 141,0 \\
12 Tahun & 26 & $142,1 \pm 8,85$ & &
\end{tabular}

* Uji Non-parametrik

\section{TABEL 7}

\section{Korelasi TB dan RT anak laki-laki berdasarkan usia}

\begin{tabular}{lcc} 
Usia & Koefisien Korelasi $(\mathbf{r})^{*}$ & $\boldsymbol{p}$ \\
\hline 6 Tahun & - & - \\
7 Tahun & 0,825 & $<0,001$ \\
8 Tahun & 0,875 & $<0,001$ \\
9 Tahun & 0,856 & $<0,001$ \\
10 Tahun & 0,930 & $<0,001$ \\
11 Tahun & $0,900^{\mathrm{a}}$ & $<0,001$ \\
12 Tahun & 0,916 & $<0,001$ \\
\hline
\end{tabular}

* Uji Korelasi Pearson

${ }^{a}$ Uji Korelasi Spearman

\section{TABEL 8}

Hasil analisis regresi linier RT sebagai prediktor TB anak laki-laki bedasarkan usia

\begin{tabular}{lcccccc} 
Usia & $\begin{array}{c}\text { Koefisien } \\
\text { Korelasi }\end{array}$ & $\begin{array}{c}\text { Standard } \\
\text { Error }\end{array}$ & $\begin{array}{c}\mathbf{R}^{\mathbf{2}} \\
\mathbf{( \% )}\end{array}$ & $\boldsymbol{p}$ & a & - \\
\hline 6 Tahun & - & - & - & - & - & 0,750 \\
7 Tahun & 0,825 & 2,790 & 66,6 & $<0,001$ & 30,547 & 0,801 \\
8 Tahun & 0,875 & 2,471 & 75,4 & $<0,001$ & 24,119 & 0,801 \\
9 Tahun & 0,856 & 2,882 & 72,4 & $<0,001$ & 26,190 & 0,906 \\
10 Tahun & 0,930 & 2,390 & 86,1 & $<0,001$ & 2,218 & 0,801 \\
11 Tahun & 0,908 & 2,769 & 81,9 & $<0,001$ & 26,117 & 0,773 \\
12 Tahun & 0,916 & 3,058 & 83,2 & $<0,001$ & 31,881 &
\end{tabular}

adalah 12 tahun dengan rerata usia 9,46 \pm 1,69 tahun. Pengukuran antropometri dilakukan terhadap responden untuk diketahui data tinggi badan dan rentang tangan.
Berdasarkan analisis regresi linier sederhana, maka rumus perhitungan umum estimasi tinggi badan anak laki-laki adalah TB $=15,615+0,879 \mathrm{RT}\left(\mathrm{r}=0,956, \mathrm{R}^{2}\right.$ $=91,7 \%$ ) dan anak perempuan adalah $\mathrm{TB}=17,108+0,869$ 


\section{TABEL 9}

\section{Persamaan regresi TB dan $\mathrm{RT}$ anak laki-laki berdasarkan usia}

Usia

6 Tahun

7 Tahun

8 Tahun

9 Tahun

10 Tahun

11 Tahun

12 Tahun
Persamaan Regresi

$$
\begin{aligned}
& \text { TB }=30,547+0,750 \text { RT }\left(r=0,825, R^{2}=66,6 \%\right) \\
& \text { TB }=24,119+0,801 \text { RT }\left(r=0,875, R^{2}=75,4 \%\right) \\
& \text { TB }=26,190+0,801 \text { RT }\left(r=0,856, R^{2}=72,4 \%\right) \\
& \text { TB }=12,218+0,906 \text { RT }\left(r=0,930, R^{2}=86,1 \%\right) \\
& \text { TB }=26,117+0,801 \text { RT }\left(r=0,908, R^{2}=81,9 \%\right) \\
& \text { TB }=31,881+0,773 \text { RT }\left(r=0,916, R^{2}=83,2 \%\right)
\end{aligned}
$$

\section{TABEL 10}

Hasil pengukuran antropometri anak perempuan berdasarkan usia

\section{Usia}

$n$

Tinggi Badan

6 Tahun

2

7 Tahun

8 Tahun

9 Tahun

10 Tahun

11 Tahun

12 Tahun

$115,3 \pm 9,33$
$120,6 \pm 5,96$
$121,5 \pm 5,59$
$130,4 \pm 6,76$
$134,3 \pm 7,58$
$139,9 \pm 7,68$
$144,7 \pm 4,79$

Rerata \pm SB

Rentang Tangan
$113,6 \pm 7,78$
$119,2 \pm 7,32$
$120,4 \pm 6,73$
$131,2 \pm 7,29$
$133,9 \pm 7,64$
$141,2 \pm 8,68$
$145,4 \pm 6,43$

\section{TABEL 11}

\section{Korelasi TB dan RT anak perempuan berdasarkan usia}

\begin{tabular}{lcc} 
Usia & Koefisien Korelasi $(\mathbf{r})^{*}$ & $\boldsymbol{p}$ \\
\hline 6 Tahun & - & - \\
7 Tahun & 0,940 & $<0,001$ \\
8 Tahun & 0,928 & $<0,001$ \\
9 Tahun & 0,938 & $<0,001$ \\
10 Tahun & 0,925 & $<0,001$ \\
11 Tahun & 0,941 & $<0,001$ \\
12 Tahun & 0,868 & $<0,001$
\end{tabular}

* Uji Korelasi Pearson

RT $\left(r=0,972, R^{2}=94,9 \%\right)$.

Berdasarkan hasil analisis regresi linier sederhana terhadap tinggi badan dan rentang anak laki-laki per usia, didapatkan persamaan khusus pada Tabel 9.
Berdasarkan hasil analisis regresi linier sederhana terhadap tinggi badan dan rentang anak perempuan berdasarkan usia, didapatkan persamaan khusus seperti pada Tabel 13. 


\section{TABEL 12}

Hasil analisis regresi linier RT sebagai prediktor TB responden perempuan berdasarkan usia

\begin{tabular}{lcccccc|}
\hline Usia & $\begin{array}{c}\text { Koefisien } \\
\text { Korelasi }\end{array}$ & $\begin{array}{c}\text { Standard } \\
\text { Error }\end{array}$ & $\begin{array}{c}\mathbf{R}^{2} \\
\mathbf{( \% )}\end{array}$ & $\boldsymbol{p}$ & $\mathbf{a}$ & b \\
\hline 6 Tahun & - & - & - & - & - & - \\
7 Tahun & 0,940 & 2,071 & 87,9 & $<0,001$ & 29,476 & 0,764 \\
8 Tahun & 0,928 & 2,124 & 85,6 & $<0,001$ & 28,660 & 0,771 \\
9 Tahun & 0,938 & 2,408 & 87,3 & $<0,001$ & 16,356 & 0,869 \\
10 Tahun & 0,925 & 2,967 & 84,7 & $<0,001$ & 11,347 & 0,918 \\
11 Tahun & 0,941 & 2,629 & 88,3 & $<0,001$ & 22,269 & 0,833 \\
12 Tahun & 0,868 & 2,473 & 73,4 & $<0,001$ & 50,476 & 0,648 \\
\hline
\end{tabular}

TABEL 13

Persamaan regresi TB dan $\mathrm{RT}$ anak perempuan berdasarkan usia

Usia

Persamaan Regresi

$\begin{array}{lc}6 \text { Tahun } & - \\ 7 \text { Tahun } & \mathrm{TB}=29,476+0,764 \mathrm{RT}\left(r=0,940, \mathrm{R}^{2}=87,9 \%\right) \\ 8 \text { Tahun } & \mathrm{TB}=28,660+0,771 \mathrm{RT}\left(r=0,928, \mathrm{R}^{2}=85,6 \%\right) \\ 9 \text { Tahun } & \mathrm{TB}=16,356+0,869 \mathrm{RT}\left(r=0,856, \mathrm{R}^{2}=72,4 \%\right) \\ 10 \text { Tahun } & \mathrm{TB}=11,347+0,918 \mathrm{RT}\left(r=0,925, \mathrm{R}^{2}=84,7 \%\right) \\ 11 \text { Tahun } & \mathrm{TB}=22,269+0,833 \mathrm{RT}\left(r=0,941, \mathrm{R}^{2}=88,3 \%\right) \\ 12 \text { Tahun } & \mathrm{TB}=50,476+0,648 \mathrm{RT}\left(r=0,868, \mathrm{R}^{2}=73,4 \%\right)\end{array}$

Hasil penelitian terhadap total 335 anak usia 6-12 tahun menunjukkan bahwa 172 anak (51,3\%) memiliki rentang tangan yang lebih panjang dibandingkan dengan tinggi badan dan 156 anak (46,6\%) memiliki rentang tangan yang lebih pendek dari tinggi badan, sedangkan 7 anak $(2,1 \%)$ lainnya memiliki rentang tangan yang sama dengan tinggi badan. Berdasarkan usia dan jenis kelamin, anak laki-laki usia 8-12 tahun cenderung memiliki rentang tangan yang lebih panjang dibandingkan dengan tinggi badan, sedangkan pada usia 7 tahun cenderung tinggi badan lebih panjang dibandingkan dengan rentang tangan. Anak perempuan usia 9 dan 11 tahun cenderung memiliki rentang tangan yang lebih panjang dibandingkan dengan tinggi badan, sedangkan pada usia $7,8,10$, dan 12 tahun cenderung memiliki rentang tangan yang lebih pendek dibandingkan tinggi badan. Rentang tangan idealnya memiliki perbedaan $1 \mathrm{~cm}$ lebih pendek daripada tinggi badan hingga sama ukurannya dengan tinggi badan. ${ }^{12}$ Hasil penelitian Zverev dan Chisi di Malawi, Afrika, menjelaskan bahwa rentang tangan anak laki-laki usia 6-15 tahun dan anak perempuan usia 10-15 tahun lebih panjang dibandingkan dengan tinggi badan. ${ }^{5}$
Hal ini menunjukkan bahwa perbandingan tinggi badan dan rentang tangan akan berbeda sesuai dengan faktor usia, jenis kelamin dan suku bangsa.

Menurut Munjal Y. dalam buku API Textbook of Medicine menyatakan bahwa rentang tangan anak lakilaki lebih pendek dibandingkan tinggi badan sebelum usia 10-11 tahun sedangkan anak perempuan sebelum usia 11-14 tahun. Setelah usia tersebut, rentang tangan akan sama atau lebih panjang dari tinggi badan yang disebabkan oleh faktor hormonal. ${ }^{13}$ Anak dengan rentang tangan yang lebih panjang dibandingkan tinggi badan sebelum memasuki masa pubertas merupakan salah satu indikasi adanya penyakit genetik yang mempengaruhi proporsi tubuh seperti Marfan's syndrome dan Klinefelter syndrome. ${ }^{14}$

Anak perempuan usia 11 dan 12 tahun memiliki rerata tinggi badan dan rentang tangan yang lebih tinggi dibandingkan dengan anak laki-laki pada kelompok usia yang sama. Hasil ini juga didukung oleh penelitian Dimeglio A. yang mengemukakan bahwa terdapat perbedaan kecepatan pertumbuhan pada anak perempuan usia 11-13 tahun akibat pengaruh masa 
pubertas. $^{15}$

Hasil penelitian mengenai tinggi badan dan rentang tangan ini secara umum menunjukkan adanya korelasi positif bermakna dengan kekuatan korelasi sangat kuat, baik untuk anak laki-laki $(\mathrm{r}=0,956)$ maupun anak perempuan $(r=0,972)$. Hasil tersebut didukung oleh penelitian Zverev dan Chisi di Malawi yang mengemukakan bahwa terdapat korelasi yang sangat kuat antara kedua variabel tersebut pada anak laki-laki $(\mathrm{r}=0,983)$ dan perempuan $(\mathrm{r}=0,986)$ usia 6-15 tahun. ${ }^{5}$ Penelitian lain di India mengemukakan adanya korelasi sangat kuat pada responden laki-laki dewasa $(\mathrm{r}=0,806)$ dan responden perempuan dewasa $(r=0,866) .{ }^{4}$ Adanya faktor suku bangsa akan berpengaruh terhadap hasil tinggi badan berdasarkan parameter rentang tangan, sehingga rumus perhitungan tinggi badan di tiap negara dan suku bangsa akan berbeda.

Korelasi tinggi badan dan rentang tangan yang dihitung pada tiap kelompok usia berdasarkan jenis kelamin juga memiliki nilai korelasi yang sangat kuat, namun nilai tersebut masih lebih rendah dibandingkan dengan nilai korelasi berdasarkan jenis kelamin secara umum. Hal ini dapat disebabkan jumlah sampel yang terbagi berdasarkan usia menjadi lebih sedikit, sehingga menyebabkan nilai koefisien korelasi tiap usia lebih rendah dari koefisien korelasi umum.

Variabel rentang tangan dapat berperan menjadi prediktor tinggi badan dengan persentase yang lebih tinggi pada kedua jenis kelamin apabila menggunakan persamaan umum pada anak laki-laki dan perempuan $\left(\mathrm{R}^{2}=91,7 \%, \mathrm{R}^{2}=94,9 \%\right)$, akan tetapi pendekatan berdasarkan jenis kelamin per usia lebih bersifat ilmiah dan spesifik. Hasil penelitian menunjukkan bahwa 54\% dari total responden memiliki estimasi tinggi badan mendekati tinggi badan sesungguhnya dengan menggunakan rumus estimasi per usia dan jenis kelamin. Berdasarkan hal tersebut, persamaan khusus estimasi tinggi badan per usia subyek memiliki nilai klinis yang lebih baik dibandingkan dengan persamaan umum.

\section{SIMPULAN}

1) Sebanyak $51,3 \%$ anak memiliki rentang tangan yang lebih panjang dibandingkan dengan tinggi badan, $46,6 \%$ anak memiliki rentang tangan yang lebih pendek dibandingan dengan tinggi badan, dan 2,1\% anak memiliki rentang tangan yang sama dengan tinggi badan.

2) Rentang tangan memiliki korelasi yang sangat kuat dengan tinggi badan sehingga dapat digunakan sebagai parameter untuk menghitung estimasi tinggi badan dengan persamaan umum:

$$
\begin{aligned}
\text { TB anak laki-laki }= & \begin{array}{l}
15,615+0,879 \mathrm{RT} \\
\\
\left(\mathrm{r}=0,956, \mathrm{R}^{2}=91,7 \%\right)
\end{array}
\end{aligned}
$$

$$
\begin{aligned}
\text { TB anak perempuan }= & \begin{array}{l}
17,108+0,869 \mathrm{RT} \\
\\
\left(\mathrm{r}=0,974, \mathrm{R}^{2}=94,9 \%\right)
\end{array}
\end{aligned}
$$

3) Persamaan khusus estimasi tinggi badan berdasarkan usia dan jenis kelamin, antara lain:

Laki-laki :

7 Tahun $\mathrm{TB}=30,547+0,750 \mathrm{RT}(\mathrm{r}=0,825, \mathrm{R} 2=66,6 \%)$

8 Tahun $\mathrm{TB}=24,119+0,801 \mathrm{RT}(\mathrm{r}=0,875, \mathrm{R} 2=75,4 \%)$

9Tahun $\mathrm{TB}=26,190+0,801 \mathrm{RT}(\mathrm{r}=0,856, \mathrm{R} 2=72,4 \%)$

10 Tahun $\mathrm{TB}=12,218+0,906 \mathrm{RT}(\mathrm{r}=0,930, \mathrm{R} 2=86,1 \%)$

11 Tahun $\mathrm{TB}=26,117+0,801 \mathrm{RT}(\mathrm{r}=0,908, \mathrm{R} 2=81,9 \%)$

12 Tahun $\mathrm{TB}=31,881+0,773 \mathrm{RT}(\mathrm{r}=0,916, \mathrm{R} 2=83,2 \%)$

Perempuan:

7 Tahun $\mathrm{TB}=29,476+0,764 \mathrm{RT}(\mathrm{r}=0,940, \mathrm{R} 2=87,9 \%)$

8 Tahun $\mathrm{TB}=28,660+0,771 \mathrm{RT}(\mathrm{r}=0,928, \mathrm{R} 2=85,6 \%)$

9Tahun $\mathrm{TB}=16,356+0,869 \mathrm{RT}(\mathrm{r}=0,856, \mathrm{R} 2=72,4 \%)$

10 Tahun $\mathrm{TB}=11,347+0,918 \mathrm{RT}(\mathrm{r}=0,925, \mathrm{R} 2=84,7 \%)$

11 Tahun $\mathrm{TB}=22,269+0,833 \mathrm{RT}(\mathrm{r}=0,941, \mathrm{R} 2=88,3 \%)$

12 Tahun $\mathrm{TB}=50,476+0,648 \mathrm{RT}(\mathrm{r}=0,868, \mathrm{R} 2=73,4 \%)$

\section{DAFTAR PUSTAKA}

1. Unicef Statistics [Internet]. 2015 [Cited 2015, February 21]. Available from : http://data.unicef.org/nutrition/ malnutrition.

2. Departemen Ilmu Kesehatan Anak Fakultas Kedokteran Universitas Diponegoro RSUP Dr. Kariadi Semarang. Buku Ajar Ilmu Kesehatan Anak. Semarang : Departemen Penerbit Universitas Diponegoro; 2011;65-68.

3. Canadian Institute of Health Information. Improving the Health of Canadians [Internet]; 2004. [Cited 2014, November 8]

4. Shah, R.K., Nirvan, A.B., Patel, J.P., Patel, B., Kanani, S. Estimating Stature From Arm Span Measurement in Gujarat Region. GCSMC J Med Sci [Internet]. 2013 [Cited 2014, November 6];2(2):30-32.

5. Zverev, Y., Chisi, J. Estimating Height from Arm Span Measurement in Malawian Children. Coll. Antropol. [Internet]. 2004 [Cited 2014, November 6]; 29(2):469-473.

6. Neyestani, T.R., Dad-khah, M., Haidari. H., Zowghi, T., Maddah, M., Nematy, M., et al. Determination of the Actual Height Predictors in Iranian Healthy Children. Acta Medica Iranica [Internet]. 2011 [Cited 2014, November 7]; 49(3):173-178.

7. Sah, R.P., Kumar, A., Bhaskar, R.K. Body Height and its Estimation Utilizing Arm Span Measurements In Population of Birgunj Area of Nepal : An Anthropometric Study. Journal of College of Medical Sciences-Nepal [Internet]. 2013 [Cited 2014, November 5]; 9(4):9-14.

8. Hossain, S., Begum, J.A., Akhter, Z. Measurement of Stature from Arm-span An Anthropometric Study on Garo Tribal Bangladeshi Females. Bangladesh J. Anat. [Internet]. 2011 [Cited 2014, November 7]; 9(1):5-9.

9. Chawla, M., Rajkumar, Tomar, S., Ashoka, R. The Relationship Between Arm Span and Height in Adult Males of North Indian Punjabi Population. Journal of Evolution of Medical and Dental Science [Internet]. 2013 [Cited 2014, November 6]; 2(4):332-339.

10. Jamir, L., Kalaivani, M., Nongkynrih, B., Misra, P., Gupta, S.K. Relationship Between Arm Span and Height Among Elderly Persons in a Rural Area of Ballabgarh, Haryana. Indian Journal of Medical Specialities [Internet]. 2013 [Cited 2014, November 6]; 4(2):248-253.

11. Mohanty, S.P.,Babu, S.S., Nair, N.S. The Use of Arm Span as a 
Predictor of Height: A Study of South Indian Women. Journal of Orthopaedic Surgery [Internet]. 2001 [Cited 2014, November 7]. 9(1):19-23.

12. Ball J., Dains J., Flynn J., Solomon B., Stewart R. Seidel's guide to physical examination. Missouri: Elsevier Health Sciences; 2014. 87.

13. Munjal Y. API Textbook of Medicine Ninth Edition. Mumbai: Association of Physicians of India; 2012. 447
14. Bojesen A, Gravholt $\mathrm{CH}$. Klinefelter syndrome in clinical practice. Nat Clin Pract Urol [Internet]. 2007[Cited 2015, July 4].4(4):192-204.

15. Dimeglio, A. Growth in Pediatric Orthopaedics. Journal of Pediatric Orthopaedics [Internet]. 2001. [Cited 2015, February 3]. 21:549-555. 